\title{
Interactive comment on "Total nitrate uptake by an invasive benthic foraminifer in marine sediments" by Constance Choquel et al.
}

Anonymous Referee \#2

Received and published: 17 September 2020

This study points out the importance of benthic foraminifera in the marine nitrogen cycle. Denitrification and oxygen respiration of the abundant and non-indigenous species Nonionella sp. T1 in the Gullmar Fjord were measured. Further, a state-of-the-art method was applied to compare the distributions of benthic foraminifera and the availability of sedimentary nitrate. Additionally, the contribution of Nonionella sp. T1 to the benthic denitrification was quantified and revealed, that this species has a strong impact on the nitrogen cycle at an oxic station at the Swedish Gullmar Fjord. I have two points to consider:

1)The title of the study implies, that the work focuses on total nitrate uptake of a specific benthic foraminifer. However, the emphasis of the first part in the discussion of this study implies a thorough taxonomic investigation of the Fjord fauna, which is not 
the case in this study. I agree with the authors, that there is an ongoing change in the benthic foraminiferal community of the Gullmar Fjord. But to verify this trend and to discuss its consequences, a longer-term monitoring study observing seasonal fluctuations of the benthic foraminiferal community together with environmental parameters at several stations within the fjord is necessary. Further, a more detailed comparison with previous literature would be necessary. I think the authors should point out, that such monitoring studies (including the $63-125 \mu \mathrm{m}$ size fraction) are important for the future, specifically considering the new observations of this study.

2)I agree with the author of the short comment considering the invasive status of Nonionella sp. T1. Certainly, this species is proven to be non-indigenous. However, the actual invasive status of this species is not proven yet. It is not yet clear, if the occurrence of Nonionella sp. T1 is responsible for the disappearance of any other species in the Fjord, nor is there any evidence, that this species is harmful for the ecosystem of the Gullmar Fjord. On the contrary, the authors point out, that this species might even be of advantage for the trophic status of the fjord. It is important to stick with correct ecological terminology to avoid confusion in further research. I would recommend to change the term 'invasive' to 'non-indigenous'.

Additionally, I would like to add a few technical corrections and minor remarks:

Introduction:

Line 29: 'and thereby to survive' should be 'and thereby survive'

Line 32: 'This study focus on...' should be 'This study focuses on...'

Material and Methods:

Line 127: 'Fixed samples were sieved and the $>100 \mu \mathrm{m}$ fraction was examined...' Did Printer-friendly version you remove any larger meiofauna e.g. by sieving through a larger sieve $(5 \mathrm{~mm}, 2 \mathrm{~mm}$, $1 \mathrm{~mm})$ ? If so, this should be mentioned too, since adults of larger denitrifying genera

e.g. Globobulimina often cannot pass through a $1 \mathrm{~mm}$ sieve. 


\section{Discussion:}

Line 292: I would consider to change the title of this section into something like: 'Abundance of Nonionella sp. T1 in comparison with other species'

Line 315: I think there is something a little bit wrong with this sentence. Should it be something like: 'That the foraminiferal fauna described in the present study differs, is the consequence...'

Line 327: Did Polodova Asteman and Schönfeld (2015) sample the same location at the oxic part of the fjord?

Line 359: Could propagules also be a reason for the survival or re-appearance of the non-denitrifying species in the hypoxic part of the fjord?

Line 392: I would be careful with this consideration, because other well oxygenated areas of the Fjord might be dominated by other species - depending on depth or other environmental parameters.

\section{Figures:}

Figure 6: It should be 'Depth (mm)' for GF17-3A and 3C and GF17-1A and $1 \mathrm{C}$ and not Depth (cm).

Interactive comment on Biogeosciences Discuss., https://doi.org/10.5194/bg-2020-287, 2020. 